largely concerned with the prevention of malaria, and in Northern Rhodesia they had been able to reduce the mortality from this disease among the European workers in the copper mines from 22 to 9 , and among the natives from 31 to 5 , per 1,000 .

\section{Meteorological Service for Indian Air Routes}

"Mrteorological Organisation for AIrmen, 1937 ", is the title of a pamphlet compiled under the direction of Dr. C. W. B. Normand, Director-General of Observatories, India Meteorological Department, for the benefit of airmen flying anywhere between the Persian Gulf and Burma (Delhi : Manager of Publications. 2s. 3d.). It describes the organization maintained by the India Meteorological Department on behalf of aviation, the nature of the information about current weather that is obtainable from that organizution, and all that an airman requires to obtain that part of the information which he may require on any flight. Full information in regard to the latter must include the addresses and telephone numbers of officers responsible under the DirectorGeneral for particular parts of the whole area dealt with, their office hours, and the times at which they complete synoptic weather charts, if the airman is to make the most of the information available. It may be noted, however, that on the trans-India air route between Karachi and Victoria Point, Burma, the issue of different kinds of meteorological message by wireless to all the main aerodromes has been organized on a routine basis and the latest information can be obtained from weather notice boards at such aerodromes; alternatively, it can be obtained by the airman by wireless while he is in flight. All these points are systematically treated in a series of tables that occupy most of the pamphlet, and among these tables are the very important ones that explain the different codes which make it possible to condense much information about actual and expected weather into telegrams or wireless messages. There is a key map showing the positions of the various types of meteorological station, and the boundaries of the different forecast areas and provinces. The organization embraces the whole of Baluchistan and Burma as well as India.

\section{Royal Scottish Society of Arts}

THe Royal Scottish Society of Arts is, like its prototype the Royal Society of Arts, one of the few unspecialized learned societies. It dräws together men engaged in the pursuit of applied science and art of the most diverse kinds. In a prospectus just issued, this peculiarity is emphasized, and it will doubtless be accounted to the Society for righteousness by those who set a high value on general culture. The principal objects of the founders were "to stimulate and reward genius and mechanical industry and to afford a ready and useful medium of intercourse among men of all ranks who were engaged either in the pursuit of Science or in the various practical departments of the Arts and Manufactures". During the winter session there are fortnightly meetings at which papers are read, and a course of special lectures on a subject of general interest is given by a selected specialist. Prizes are offered for inventions and communications. The Council desires to suggest, especially to prospective student members (for whom the annual subscription is only 5s. up to the age of twenty-three years) that attendance at the ordinary meetings and participation in discussions provides an extremely easy and really valuable means of extend. ing their general and technical education. Evidently a complete survey of adult education would not ignore the opportunities offered by this Society.

\section{Modern Sylviculture}

IN an article entitled "Revue de Sylviculture", published originally in the Revue generale des Sciences pures et appliquees (48, No. 7, April), Prof. H. Perrin deals with the practice of modern sylviculture more especially from the French point of view. He points out that in former times the forest was regarded solely as a source of supply of timber and smaller materials, on the supposition that such supplies would continue inexhaustible. Latterly, he says, there has been a swing-back, in some quarters, to this point of view. He pleads for a return to, or a continuance of faith in, the sylvicultural principles laid down by the old masters of the science or art, of whom the last century provided some of the best known. Perrin deals with the various aspects of, and factors influencing, sylvicultural practice, and details in a general manner French methods. A close acquaintance with the forest is not easy to acquire, owing to the fact that the methods of investigation common to all the biological sciences are difficult of application in the forest ; long years of observation must be passed during which generations of men succeed each other; and only continuity and persistence will result in that sylvicultural knowledge and practice which is the antithesis of the 'get rich quick' theory as applied to forest management, which has made its appearance of late years in places.

\section{The R.H.S. Lily Year-Book}

Contributions from the point of view of the practical gardener predominate in the Royal Horticultural Society's Lily Year-Book for 1937 (from the Society's Office, Vincent Square, Westminster, S.W.1, 5s. paper ; 6s. cloth ; pp. 153. Oct. 1937). Information upon the choice of lilies for all situations in the garden can be found in it, and the increasing popu. larity of Nomocharis and fritillary is reflected by several articles on these genera. Dr. W. B. Turrill contributes a useful taxonomic study on fritillaries, giving detailed descriptions of anatomy. A report of discussions upon the propagation of lilies from scales provides much practical information. Two papers, by Dr. Fred Stoker and F. C. Stern, compare lilies which will grow on lime-free and lime soil respectively. No sharp distinction can be drawn between the lily flora of these two horticultural habitats, and the absence of more scientific experiments leaves a doubt as to whether lime or some other influence is really the controlling factor. Mr. L. 